\title{
Classification of ischaemic stroke aetiology: reliability and its effect on trial 'power'
}

\section{BACKGROUND}

Increasingly, stroke research is concerned with interventions for particular aetiological subtypes. Inter-observer variability in aetiological classification has an impact on trial 'power'. We modelled the effect of misclassification in a hypothetical cardioembolic stroke trial and then extrapolate to Embolic Stroke of Undetermined Source (ESUS) randomised controlled trial.

\section{METHODS}

We used systematic review to quantify the reliability (inter-observer variability) of stroke classification systems.

We modelled the effect of this misclassification in a hypothetical trial of anticoagulant in cardioembolic stroke (CE) contaminated by patients with noncardioembolic (non-CE) stroke aetiology. We randomly sampled data from previous acute trials that included anticoagulant in CE and non-CE, stored within the Virtual International Stroke Trials Archive (VISTA). We described outcomes in terms of survival and stroke recurrence censored at 90 days, and used bootstrapping to describe the effect of varying misclassification rates on sample size required to detect a between group difference from intervention across 5000 permutations. (Figure 1 )

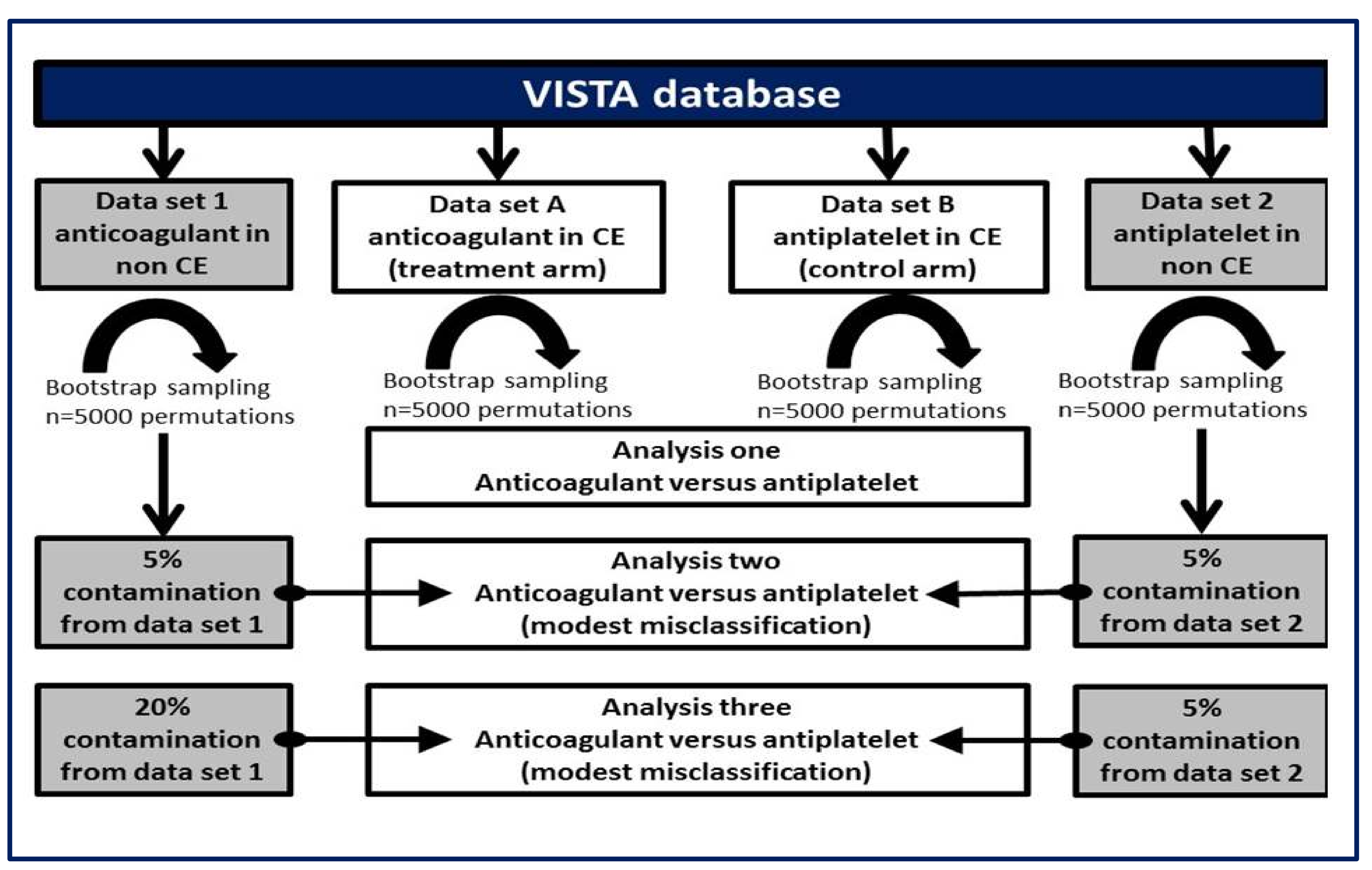

Figure 1: Bootstrapping simulations with random repetition sampling to create models to our specified sample size.

\section{RESULTS}

From 4553 titles, we found 14 articles describing the common stroke classification systems. The interobserver reliability of the classification systems varied from 'fair' to 'very good' and suggested misclassification rates of $5 \%$ and $20 \%$ for our modelling.

The hypothetical trial was able to show a difference in survival between anticoagulant and antiplatelet in CE with $\mathrm{N}=198$ both arms. Contamination of treatment and control arms with $5 \%$ misclassified participants increased $\mathrm{N}$ to 237 and with $20 \%$ misclassification increased $\mathrm{N}$ to 352. For an outcome of stroke recurrence using the same data, base-case estimate sample size was $\mathrm{n}=502$ both arms, increasing to 605 at $5 \%$ contamination and 973 at $20 \%$ contamination. (Table 1)

\begin{tabular}{|c|c|c|}
\hline $\begin{array}{c}\text { Misclassification } \\
\text { rate }\end{array}$ & Death & Recurrent stroke \\
\hline $0 \%$ & 198 & 502 \\
\hline $5 \%$ & $\begin{array}{c}237 \\
\text { (20\% increase) }\end{array}$ & $\begin{array}{c}605 \\
\text { (21\% increase) }\end{array}$ \\
\hline $20 \%$ & $\begin{array}{c}352 \\
\text { (78\% increase) }\end{array}$ & \begin{tabular}{c} 
(94\% increase) \\
\hline
\end{tabular} \\
\hline
\end{tabular}

Table 1: The required sample size for each arm of the hypothetical clinical trial according to the stroke aetiology misclassification rates.

\section{CONCLUSIONS}

Aetiological classification systems are associated with inter-observer variability and the resulting misclassification may reduce trial power. This may explain the neutral result in a recent trial of anticoagulant in patients with ESUS. 